\title{
Research on armored equipment IETM data
}

\author{
Guohui WANG, Tiejun ZHAO \\ Armament Science and Technology, Army Academy of Armored Forces, 100072 Beijing, China
}

\begin{abstract}
This thesis studies armored equipment IETM data concerning its huge volume, various forms and the difficulty to collect, process, store and manage. Special focuses are on data module requirements list and the establishment of relation data model after the analysis of data features and the creation of relation data model by S1000D, which provide data basis for system development.
\end{abstract}

\section{Introduction}

Under the background of information warfare, armored equipment also joins in information development. Its integration of various high technologies and complicated structures makes it complex to operate and difficult to preserve, maintain and analyze faults. Military at the basic level and maintenance personnel mainly depend on paper material. The huge amount, repeated content and lagged upgrading make material management a hard work and bring problems on validity and maintenance. Such inconvenience also makes it hard for personnel to learn and look up materials, which seriously restricts the promotion and improvement of arm forces and safeguard. IETM can solve the problems mentioned above and improve the information level of equipment support, therefore, which is necessary to develop armed equipment IETM $^{[1]}$. Paperless technical information, data sharing and interoperability can be realized with IETM system, which is convenient for data query and usage, and can bring tremendous benefits for military and economy. The procedure of the development of armed equipment IETM is as follow: program requirement, technology specification, information granularity, information set, Data Model Requirement List(DMRL), Data Model(DM), charts, multimedia materials, common source data base (CSDB) and publications. Data information of armed equipment includes technical descriptions, manuals, maintenance outlines, engineering drawings, simulation models, videos and animations. This article provide a reference for the development of armored equipment IETM system. The thesis studies how there data are collected, organized and processed to generate IETM system information.

\section{Features of armored equipment data}

The huge amount of data. From the structure of the entire equipment to the parameter of every part, there is an incredible amount of data. Meanwhile, a large amount of data will also be produced in the equipment improvement, use, maintenance and management. The data volume of a type of US tank reaches 43,000 pages and such data must be used in equipment maintenance, management and support $^{[2]}$. However, it is difficult to quickly find valid data from a large amount of data. Hence, how to effectively store and manage data is an urgent issue to be solved.

The integrity of the data. The hierarchical structures of armored equipment are equipment, systems, subsystems, main components, and little detachable parts. Every level has basic attributes, roles, components, functions and other information. Data is structured as DM based on troop's needs. And DM is structured as database of armored equipment. Maintenance personnel need to learn the basic knowledge of the entire equipment. When they have a preliminary understanding of the equipment, they need to study the knowledge thoroughly. In this way, knowledge can be linked for better understanding, and the skill levels could be improved.

The diversity of data. In the process of equipment development, a large number of documents, drawings, tables, simulation models are produced. In the use of equipment, many videos, animations, audio, and VR are generated, which are both vivid and easy to understand. Different formats of data are compiled into different forms of IETM. Documents and forms are compiled into DM. Pictures or videos can establish contact with multiple DM. Every picture or video has a unique ICN as an identifier and they can be referred by DM through ICN.

Data redundancy. The same data may be used by different documents. Data will also be backed up, delivered or stored in different locations and on multiple computers. This will benefit to using data, securing them and preventing loss. However, when the equipment is repaired, improved, and tested, the corresponding data will also be updated, modified, deleted and added. The higher data redundancy makes it difficult for data to change. The data stored in multiple places must be completely modified. If there is any omission, the use of old data will bring serious consequences for maintenance. 


\section{To create information set}

Before system is developed, information set (IS) will be established based on the requirements of system function. IS determines the scope, depth and use of information. It is also a collection of all DM which completely describes the technical information of armored equipment. The DM is made up of the data of equipment. DM is organized in XML format. The DM type is determined according to the data requirement. And $\mathrm{DM}$ is organized into an information object according to the relevant rules. Information set includes general IS, land/navigationspecific IS and aviation-specific IS. The general IS provides description and operation information, maintenance information and diagrammatized parts information. Land/navigation-specific IS can satisfy the information set required by troops and factories.

Maintenance report IS includes introduction, index, and maintenance report. It is used for the inspection of individual parts. Circuit IS contains description information, electrical construction standards, circuit diagrams, electrical equipment installation drawings and so on. It is used for circuit maintenance. Operation IS involves overviews of armored equipment, descriptions of operational information, operating methods, procedures, precautions, and emergency operations. It provides theoretical ground for operators. Maintenance IS is composed of common faults and failure mechanisms, nondestructive testing, trouble removal methods, and anticorrosion measures. Diagrammatized parts IS is about the identification, structure, composition of individual parts and their relationship. Besides, information such as model number and manufacturer are also elaborated. Training IS involves courses, introduction, modules, and themes for personnel training. Equipment data IS includes equipment overview, equipment list, equipment, parameter list, and index number. It is used for equipment management, procurement, storage and use. Weapons loading IS contains basic information, supplementary information, loading and unloading procedures and checklists, combat round-trip procedures and checklists, and transitional service checklists. It is used to check and maintain the weapon system and to guide loading and unloading of ammunition.

IS plays an important role in the development of IETM systems. It can organize the required data based on users' needs. After the establishment of DMRL, DM is structured accordingly to complete the exploration of $\operatorname{IETM}^{[3]}$. In the use of IETM, there may be problems in correctness, completeness, and applicability. If the problem is not serious, IS needs to be modified. Otherwise, IS will be recreated.

\section{To create data module requirement list}

DMRL The DMRL is used to identify the DM needed for the project. The DMRL contains the DMC, title, version number, release date, quality, and so on. DMC is the only identifier of DM that is used for storage, management, and invoking the DM. DMC consists of the hardware/system identification section, information type section, and learning type section. The IETM coding system is composed of DMC, multimedia information control codes, publication module codes, and other information object codes. DMC is constituted of numbers and letters. The hardware/system identification section includes a model identification code (MI), a system differentiation code (SDC), a system hierarchy code (SNS), and a disassembly code / disassembly code variant (DC/DCV). The hardware/system identification section describes the equipment type and subordinated hierarchies. The information type information code/information code variant (IC/ICV), item location code (ILC) section describe equipment use, maintenance and other information categories, as well as learning type description learning, training and other information categories. The learn code/learn event code (LC/LEC) is an optional code that is used in describing auxiliary training. The armored equipment code is based on the S1000D specification. $Z$ symbolizes the armored equipment, and $\mathrm{P}$ the weapon system code. Concerning the actual situation of armored equipment, a certain type of tank DMRL is defined as Table 1:

Table 1. A certain type of tank DMRL

\begin{tabular}{|c|c|c|c|c|c|c|c|}
\hline \multicolumn{7}{|c|}{ DMC } & Name \\
\cline { 1 - 5 } MI & $\begin{array}{c}\text { S } \\
\text { D } \\
\text { C }\end{array}$ & SNS & $\begin{array}{c}\text { DC/D } \\
\text { CV }\end{array}$ & $\begin{array}{c}\text { IC/ } \\
\text { ICV }\end{array}$ & ILC & LC/LEC & \\
\hline ZTZ & B1 & $\begin{array}{c}\text { C00P } \\
001\end{array}$ & P01 & A & A & 1 & Monoblock \\
\hline ZTZ & B1 & $\begin{array}{c}\text { C00P } \\
002\end{array}$ & P02 & A & A & 2 & Gun breech \\
\hline ZTZ & B1 & $\begin{array}{c}\text { C00P } \\
003\end{array}$ & P03 & A & A & 3 & $\begin{array}{c}\text { Connecting } \\
\text { cylinder }\end{array}$ \\
\hline ZTZ & B1 & $\begin{array}{c}\text { C00P } \\
004\end{array}$ & P04 & A & A & 4 & $\begin{array}{c}\text { Evacuating } \\
\text { equipment }\end{array}$ \\
\hline
\end{tabular}

\section{Data module research}

\subsection{Contents}

$\mathrm{DM}$ is an ASCII file and the smallest information unit describing a certain information. Operational use information, management information and maintenance information are used to establish DM in the operation of armored equipment to maximize data reuse, reconstruction, and sharing. It also benefits to management, maintenance, and storage. DM consists of the IDSTATUS part and CONTENT part. In IETM, data in other formats such as charts and multimedia are not stored directly in the DM but are referenced in the DM. They each is given an information control number (ICN), which is used by IETM to control and invoke charts and other forms of data.

Armored equipment description information is the composition, structure, performance, parameter, working principle and other data of every part of armored equipment. It can spread the knowledge of armored equipment and allow officers and soldiers to have a preliminary understanding of the equipment. The contents are rich including charts, videos with strong performance 
and easy-to-understand images. The procedural information of armored equipment is composed of hierarchical maintenance data and is divided into preprepared information, maintenance procedures, and finishing operations, and is used to guide maintenance personnel. Before the maintenance, the tools and data need to be prepared step by step according to the repair procedures. Tools should be put back when the work is done. The steps of the program are reflected in <stepl> and can be decomposed into several steps, represented by elements $<$ step2>, $<$ step3 $>$.

Operation methods, technical procedures, and precautions are presented through video, text, and flowcharts to enable officers and soldiers to learn. Operator information is a working requirement containing operating conditions, function checks, operations, and operation completion. Maintenance planning information consists of system task information, inspection information, and time limit information and is used to guide the maintenance personnel for precaution and maintenance. Fault information consists of fault reporting and fault isolation. The fault report includes observed fault information, identified fault information, associated fault information, and related information of fault parts. Fault isolation includes fault codes, fault descriptions, and isolation procedures. Diagrammatized parts information, which consists of mechanical drawings, names, models and CAD drawings, is the basis for the exemption of the limit. Equipment management information includes equipment strength, affiliation units, persons in charge, use, and resume data.

\subsection{To create a data model}

The S1000D standard specifies the use of XML to organize DM. IETM data is built into a relational model and stored in the database. A relational model is a twodimensional table that represents data structure, which is also a relationship, among columns represent attributes and rows represent tuples. Every header is a structure of relation. There is only one kind of data structure in the relational model. The relational data model is based on set theory, which means that a relationship can only contain one primary key. Primary key is defined from multiple candidate keys. There are three types of relationships: basic tables, query tables, and view tables. The basic table is the actual stored logical table. The query table is the table generated by the query result. The view table is a table exported by a basic table or other view tables and does not correspond to the actual storage data. The DMRL in Table 1 is established with a certain type of tank gun body relation data model, as shown in Table 2. Table 2 clearly describes the content, attributes, structure, and connections of data as an example of the model, which means that all equipment data must establish a relational model.

Table 2. Tank gun body relation data model

\begin{tabular}{|c|c|c|c|c|c|}
\hline DMC & Name & Type & $\begin{array}{c}\text { Data } \\
\text { content }\end{array}$ & Quality & Life \\
\hline
\end{tabular}

\begin{tabular}{|c|c|c|c|c|c|}
\hline $\begin{array}{c}\text { ZTZB } \\
\text { 1C00P } \\
\text { 001P0 } \\
\text { 1AA1 }\end{array}$ & Barrel & $* *$ & $\begin{array}{c}\text { XML } \\
\text { text }\end{array}$ & $* * \mathrm{~kg}$ & $\begin{array}{c}* * * \\
\text { hour }\end{array}$ \\
\hline $\begin{array}{l}\text { ZTZB } \\
\text { 1C00P } \\
\text { 002P0 } \\
\text { 2AA2 }\end{array}$ & Gun breech & $* *$ & $\begin{array}{c}\text { XML } \\
\text { text }\end{array}$ & $* * \mathrm{~kg}$ & $\begin{array}{c}* * * \\
\text { hour }\end{array}$ \\
\hline $\begin{array}{l}\text { ZTZB } \\
\text { 1C00P } \\
\text { 003P0 } \\
\text { 3AA3 }\end{array}$ & $\begin{array}{c}\text { Connecting } \\
\text { cylinder }\end{array}$ & $* *$ & $\begin{array}{c}\text { XML } \\
\text { text }\end{array}$ & $* * \mathrm{~kg}$ & $* * * \mathrm{~h}$ \\
our \\
\hline $\begin{array}{l}\text { ZTZB } \\
\text { 1C00P } \\
\text { 004P0 } \\
\text { 4AA4 }\end{array}$ & Exhauster & $* *$ & $\begin{array}{c}\text { XML } \\
\text { text }\end{array}$ & $* * \mathrm{~kg}$ & $\begin{array}{c}* * * \\
\text { hour }\end{array}$ \\
\hline
\end{tabular}

Armored equipment requires a high level of technical skills for maintenance personnel because they need to inquire a lot of maintenance materials when they work. Maintenance tasks include fault diagnosis, fault reasoning and troubleshooting. The IETM maintenance subsystem can assist maintenance, provide technical support for maintenance personnel, and reduce the technical requirements of maintenance operations. It also guides the maintenance personnel and conducts interactive maintenance through the "one answer, one answer" approach. When the maintenance personnel enter faults, the subsystem will give the options after the corresponding calculation. Maintenance personnel make choices concerning the equipment. The subsystem prompts for the next step and repeats until faults are removed. Maintenance syllabus of armored equipment, procedures, guidelines, and other data are collected and converted into maintenance information set and DMRLs, which then become data relationship models. As an example of a breech latch fault, a relational data model is shown in Table 3 . The relational model organizes various entity information together and establishes the connection among entities, which is the basis for the next step to establish a database.

Table 3. Data model of breechblock fault relationship

\begin{tabular}{|c|c|c|c|c|}
\hline $\begin{array}{c}\text { Mainten } \\
\text {-ance } \\
\text { Number }\end{array}$ & $\begin{array}{c}\text { Equip- } \\
\text { ment } \\
\text { coding }\end{array}$ & $\begin{array}{c}\text { Fault } \\
\text { locatio } \\
\text { n }\end{array}$ & $\begin{array}{c}\text { Failure } \\
\text { name }\end{array}$ & $\begin{array}{c}\text { Maintenance } \\
\text { method }\end{array}$ \\
\hline 001 & ZTZ & $\begin{array}{l}\text { Breech- } \\
\text { block }\end{array}$ & $\begin{array}{c}\text { Breechbloc } \\
\text { k is not } \\
\text { closed }\end{array}$ & $\begin{array}{c}\text { Repair of } \\
\text { original parts }\end{array}$ \\
\hline 002 & ZTZ & $\begin{array}{l}\text { Breech- } \\
\text { block }\end{array}$ & $\begin{array}{c}\text { The } \\
\text { breechbloc } \\
\text { k latch did } \\
\text { not open } \\
\text { after firing }\end{array}$ & $\begin{array}{c}\text { Repair of } \\
\text { original parts }\end{array}$ \\
\hline 003 & ZTZ & $\begin{array}{l}\text { Breech- } \\
\text { block }\end{array}$ & $\begin{array}{c}\text { Cartridge } \\
\text { can not be } \\
\text { pulled out }\end{array}$ & $\begin{array}{c}\text { Alternate } \\
\text { maintenance }\end{array}$ \\
\hline 004 & ZTZ & $\begin{array}{l}\text { Breech- } \\
\text { block }\end{array}$ & $\begin{array}{c}\text { The } \\
\text { breechbloc } \\
\text { k cannot be } \\
\text { controlled } \\
\text { in the open } \\
\text { breechbloc } \\
\text { k position }\end{array}$ & \\
\hline & $\begin{array}{c}\text { Alternate } \\
\text { maintenance }\end{array}$ \\
\hline
\end{tabular}




\section{Conclusion}

As the fast growing pace of the information buildup of armored equipment support, armored equipment ITEM is put on the agenda. ITEM has the function of maintenance assistance, training aiding, and material management, hence it is of great benefit for both military and economy. The establishment of data model is the core of system development. The thesis builds information set based on the features of armored equipment, so as to create DMRL and DMC to achieve data process and modeling, which provide complete plan for the collection, processing and modeling of armored equipment IETM data.

\section{References}

1. Z.Lei, QQ.Li, JW.He, MET, 38, 139(2015)

2. WG.Wang, B. Wang, MDT.34, 74 (2006)

3. YH.Yang, ZZ.Li , L.Zheng,AA.28, 120 (2007) 